\title{
Criminological Analysis of the Antisocial Personality of the Terrorist
}

\author{
Gabriel Tănăsescu \\ University of Craiova, Craiova, Romania, gabrieltanasescu@gmail.com
}

\begin{abstract}
This article describes the causal link between the antisocial personality of the terrorist and the suicidal behavior that preceded the passage to the criminal act. People with antisocial personality disorder are characterized as aggressive, irresponsible, cynical, impulsive, empathy-free, have a criminal behavior and know the experience of professional failure. From a psychoanalytic point of view, the terrorist has a devalued Superego, the ego is influenced by the drive of destruction, and can no longer censor the morbid demands of Id. Anticipating the sanction and assessing the consequences of the criminal act lead to the inhibition of the aggressive personality, the passage to the act being stopped by the moral barrier, by the censorship of the overwhelm in the case of a social being. The concept of radicalization is presented in comparison with the failure of social integration programs. Radicalization is preceded by suicidal behavior.
\end{abstract}

KEYWORDS: antisocial personality disorder, suicidal behavior, radicalization, Superego, passage to the act

\section{Introduction}

Radicalization is a process of behavioral transformation whereby the person discovers the aggressive motivation to passage to the act, the reason to disturb social order through terror, a process by which the person finds the inner force to use violent means against the victims who are not part of the terrorist group, which do not have the same political, cultural and religious objectives; violence can also be directed against symbolic goals (Bertjan Doosje, Fathali M Moghaddam, Arie W Kruglanski, Arjan de Wolf, Liesbeth Mann and Allard R Feddes, 2016). The purpose of radicalization is to produce arguments and justifications for committing antisocial deeds causing terror to members of societies who do not share the radical ideas of the terrorist group. The terrorist assault becomes a success for criminal groups if it causes as many victims as possible, as well as material damage, social tensions and economic decline in the segments of society.

Through radicalization, ideas of a religious nature or an ideology are expressed through intense expression of the apology of a totalitarian, anarchist, undemocratic, intolerant regime. More than $95 \%$ of terrorist attacks were organized, coordinated and executed in a group, collectively by a terrorist group. Within the group, it is easier to prepare for the attack, and at the same time within the group you develop and keep your motivational energy to commit the attack, which can sometimes be a suicide attempt (Bertjan Doosje, Fathali M Moghaddam, Arie W Kruglanski, Arjan de Wolf, Liesbeth Mann and Allard R Feddes, 2016). The individual who is radicalized must constantly keep at the intellective and emotional level the radical ideas that have caused his behavioral change, as well as the power to act unconditionally, according to the group's decisions. Members of the terrorist groups are encouraged to resist all existential challenges that could detract from their general purpose, religious fanaticism of leaders has a significant influence in many situations. Feelings of injustice, negative social experiences, discrimination and insults are always remembered by group leaders. The radicalized individual who is part of a military organized terrorist group is considered a soldier fighting in a holy war; he has no pity on the collateral victims because the war must be won by any means.

\section{Psychoanalytic aspects}

Superego is censorship, Superego is the inhibition, but at the same time Superego is born, it develops only from the relation of the Ego to the world, its freedom of manifestation, but also from the contamination of perceptions with the gross being of reality. Being influenced by the Superego authentic-presence position, the Ego-Id becomes the intermediary of the Moral Being, and at the same time a messenger of inner values sent to investigate the bonds of being with the reality of the world, provocative alterity. Ego.Id is cast into the existence of the bodily world and strives to maintain a balance between the sometimes excessive requirements of the Id, the demands of the 
social world generated by intramundal relations, and the requirements of the Superego (the plans of the moral being); these demands are sometimes torture, their fulfillment or failure to suffer the Ego, reveal the weaknesses of the personality and push the individual to anger and exhaustion. The Superego limits freedom and inhibits the requirements of the Ego-Id; In the case of the antisocial personality, which turns into a delinquent personality, sometimes the Superego is handcuffed, is closed in a state of concealment, the inhibitions and the moral court are asleep and pushed to the limit of absence, to the underground edge of the unconscious. In order to feel free to escape conditions and prejudices, the Ego must eliminate the tension caused by the censorship of the Superego; morality as an expression of the Superego's identity is held in the shadow of the unconscious, it is not activated, so the fear of rules and consequences disappears into the abyss of the perpetrator's mind without disturbing the privacy of the Ego; the state of anguish is replaced by a temporary state of well-being, of spiritual freshness; anxiety and depression sometimes crack a malignant layer over the soul's rooms, shut the individual's being, and this break of the Ego-Id that claims its freedom and the joy of living represents for a short time the saving solution. An individual with an antisocial personality is emotionally unstable, egocentric, aggressive, without too much affection for the fellow, his mood changing frequently; well-being is short-lived, invariant and degrading. The destruction drive separates the Ego from reality and thus a psychic cleavage occurs, the relationship with the outside world being affected by the uncontrollable demands of the Id, as the Ego may be affected by psychoses (Freud, 2014).

The superstition of the radical person who becomes the adept of the ideology of terrorism is killed by the criminal ego penetrated by fanaticism; the moral court no longer controls the personality of the person; through aggressive behavior, the Ego reveals his voluntary slavery to the claims and pleasures of the Id. The joy of killing, committing a suicide terrorist attack, causing the death of some people, regardless of their social condition, age, sex, religion, is the satisfaction of the demands of the vindictive Id, the death drive acts to get rid the Ego of the terrible feeling of guilt, a self-destructive feeling (New Zealand Theorist draws cold blood on innocent victims women, children, old people, men - without remorse and no inhibition, no shaking his hand, skillfully using guns and chargers, sometimes chaotic shooting in the victims already death, aggression discharged laughs and is surprised to survive the massacre). Analyzing the personality of the human being can be said that the evolution of being is related to the evolution of the Superego; matter, the being of the Id is the dark side of the person who pushes the Ego to death; the Id wants to satisfy its immediate instincts, sometimes irrespective of the consequences; the destruction drive push the interests of the Ego just now into the unconscious of the pleasures exhausted by temporary acts; through the censorship of Id's pulses, only the Superego can give the Ego the positivity of the existential project and the path to a spiritual evolution; the lack of inhibition of the Ego influenced by the destruction drive kills the Superego and at the same time kills the whole being. Victims of terrorism exist because they appear as objects of the terrorist attack, an attack produced by the perpetrator's ego.

The criminal ego of a terrorist justifies his suicidal behavior only if he succeeds in committing the moment of terror and deliberately killing as many victims as possible. From a psychoanalytic point of view, radicalization involves a radical transformation of the Ego. If until the time of radicalization the individual respected the criminal law of society and did not kill, it means that the process of radicalization decisively transforms the personality, and the genesis of aggressive compassion becomes the genesis of the justification of the terrorist act. Terror leads to chaos, social disorder, economic crises, crimes against humanity, which means that the terrorist act will always have a non-human nature. In the "Ego and Id" (1923), Freud cites G. Groddek (Das Buch vom Es, Internationaler Psychoanalytischer Verlag, 1923) "Our ego behaves alive in an essentially passive manner, because, after its expression, we are experiencing unknown forces that can not be mastered." 


\section{Preventing radicalization}

In order to prevent radicalization, vulnerable persons to radicalization must be identified; it is necessary to intervene with experienced competent officials, governmental agencies preparing courses and broadly explain the complexity and danger of radicalization; developing good practice guides to prevent and stop radicalization; promoting an ideology of violence, radicalization attracts adherents and takes place at the same time as the trigger event that removes the individual from social normality; the trigger event is sometimes influenced by life problems, negative social factors, family factors, physical health problems of the individual, or the suffering of the members of the family to which he belongs; the trigger event radically transforms the life of the individual, there is a behavior change, the attitude aggressiveness and the first elements of the suicidal behavior appear; Superego as a moral instance is kept in the darkness, personality is changing, there is a negative metamorphosis of the Ego; the religious factor and fundamentalism become important and have priority over routine and common cultural activities; the pleasure of discovering the ideologies of violence appears; rumors and emotional instability occur; the struggle for an ideal society and extremist ideas are obsessive concerns in this period; there is an interest in discovering how terrorist groups operate and the first attempts to benefit from the experience of radicalization; radicalization is a complex process and takes place in several stages, so the intervention of deradicalization through special procedures is important to happen as soon as possible; radicalization takes place in the space of a society and uses the contemporary means of communication to spread the doctrine of violence; the institutions of the national state and international institutions must take measures to prevent the recruitment of young people into terrorist organizations; access to radicalization should not be easy; the consequences of a criminal sanction (both for the perpetrator and for the closure of the closest) and the vigilance of the competent institutions fighting terrorism must become obstacles for those who want to enter the process of radicalization; if the recruits make a great effort in the radicalization process, then there is also the opportunity to intervene the process of deradicalization to determine the adherent to reject extremist ideologies and to abandon integration into the terrorist network; at the same time, effective local policies on the social reintegration of those who accept deradicalization must have positive effects; the prevention of radicalization is much more effective than the process of deradicalization of members of terrorist organizations and of the families they support.

The adept of violent radicalization can be described as an individual dissatisfied with his existential, marginalized, and unfairly excluded social strategies; its relations are unstable and short-lived; is easily influenced and conflicts with the authorities; dominated by the pulse of destruction, revenge, and sometimes greed; reacts instinctively and has affective, emotional instability; is considered the victim of the current social system; is aggressive, encompassed by religious fanaticism, without respect for social norms and without fear of legal consequences; is tired of the uncertainty about his role in social life; is not able to engage in the realization of a positive social, family, and economic project; he loses his job quickly because of divergences and religious problems; exaggerates the importance of the religious factor for the failure of social life; always finds religious arguments against a new job.

\section{Theoretical aspects regarding the personality of members of terrorist groups}

When individuals act in a group, their behavioral reactions are relatively stable, the attitudes imposed by a number of factors become similar, with the motivational inner force being generated by the extreme ideology. The organization, leadership and supervision of the terrorist group is carried out by a leader who, through authority, power and prestige, manages to dominate and exert influence on members (Tănăsescu 2012a). Within terrorist groups there are pre-established bodies that institutionalize leadership; the leader is at the same time through the leadership activities he carries out and the members' preference. For the purpose of achieving the overall goal, the leader plans and structures members' activities, his actions are based on an aggressive ideal, on the idea of eliminating the unequal distribution of power between and within countries as this will impose a new order justified by a new religion. The will to overthrow the hierarchy of social forces has a 
mystical, religious character, the motive motif identifies itself with a fighting ideal the fanaticism of members of the terrorist group allows them to be involved in suicide attempts. Active violence and unconditional obedience to the behavioral rules imposed by the group they belong to express the solidarity of the members and at the same time the effectiveness in making the most terrible terrorist attacks. The personality of the terrorist is characterized by aggressive behavior towards the dominant social structures, to the administrative and government apparatus; the terrorist engages in anti-social, destructive actions to provoke the state of terror, imbalance and political, social, economic instability. The aggressiveness of the perpetrator becomes a weapon and a form of manifestation for the realization of the extremist ideals within the fanatic groups, the purpose of the passage to the criminal acts being to frighten the population, to achieve as many collateral victims as possible, to interrupt the social activities and to destroy the perception ordinary people about the security that state structures provide.

The moral judgments of a community about the inappropriate individual reflect the contradiction between the social behavioral ideal and the concrete social reality opposite the realization of an existential commitment. The social order is characterized by unequal manifestations, by antagonisms, by the faculty of the human being to progress as a result of the preservation of human order, to accumulate certain virtues that are balanced with the degrading aspects of some of the behaviors. Good morals stimulate individual acts, although civilization has profound contradictions (Tănăsescu 2012b). The synthesis of social relationships encourages individual traits, certain psychological determinations that impose behavioral particularities. This behavioral specificity is a long-term process, which involves the development of the individual's adaptation capacities to environmental conditions as a result of learning and acquiring social rules and norms. The multiple influences that the social, political, cultural and religious environmental factors have on the individual acquire a causal dominant nature, the social framework being mobile, changing, requiring a constant effort to adapt the individual (Tănăsescu, 2012c).

\section{Conclusions}

Right-wing extremism and terrorism appear to be men's concerns, but lately we also find examples of women involved in the phenomenon of violent radicalization. Women who followed men in radicalization and terrorism radically make their children more radical, and urge them to accept the message of extremist ideologies related to terrorism. The process of deradicalization has to promote a positive speech, and it must intervene as soon as possible in children's education, to discourage any form of violence and involvement in terrorist actions.

From a criminological point of view, radicalization already means the beginning of the act. The terrorist assassination by killing victims is the killer moment of terror, but the criminal idea has formed in the personality of the terrorist since radicalization. Radicalization happens and develops in a social space within a community. Radicalization is linked to the social, political, cultural, economic and religious life of the day, and the terrorist fighter violently opposes these realities. Radicalization promotes a violent, extreme ideology, and those who adopt it disagree with the social system and the values of the communities in which they live. Sometimes the radicalization process is successful because the terrorist fighter very easily accepts the ideology of the terrorist group, and the proposed criminal behavior fits its antisocial personality.

\section{References}

Akhtar, Salman. 2018. Sources of Suffering: Fear, Greed, Guilt, Deception, Betrayal and Revenge. Bucharest: Three Publishing House.

Aniţei, Mihai, Chraif, M., Burtaverde V., and Mihăilă T. 2016. Personality Psychology Treaty. Bucharest: Three Publishing House.

Atkinson, Rita L., Atkinson Richard C., Smith, Edward E., Bem, Daryl J. 2002. Introduction to Psychology, Bucharest, Technique S.A. Publishing House.

Bertjan Doosje, Fathali M Moghaddam, Arie W Kruglanski, Arjan de Wolf, Liesbeth Mann and Allard R Feddes. 2016. “Terrorism, radicalization and de-radicalization, Current Opinion." Psychology 11: 79-84. Doi.org/10.1016/j.copsyc.2016.06.008. 
Costello, Stephen J. 2017. The Pale Criminal: Psychoanalytic Perspectives. Bucharest: Three Publishing House.

Cusson, Maurice. 2016. For an antiterrorism defensive, focused and versatile, Notes \& Syntheses. Institut pour la Justice, N 35, April 2016.

DSM-IV-TR. 2003. Diagnostic and Statistical Manual of Mental Disorders, edited by Aurel Romila, The Free Psychiatric Association in Romania Publishing House.

Freud, Sigmund. 2014. About Psychoanalysis. German translation by Daniela Stefanescu. Bucharest: Three Publishing House.

Freud, Sigmund. 2017. Psychology of the Unconscious. Bucharest: Three Publishing House.

Sartre, Jean-Paul. 2004. Being and Nothingness. Piteşti: Paralela 45 Publishing House.

Schaffer, Jack B., Rodolfa, Emil. 2019. ICD-10-CM: Casebook and Workbook for Students: Psychological and Behavioral Conditions. Bucharest: Three Publishing House.

Tănăsescu, Camil. 2012a. Criminology. Bucharest: Universul Juridic Publishing House.

Tănasescu, Camil. 2012b. Judicial Psychology. Bucharest: Universul Juridic Publishing House.

Tănăsescu, Camil 2012c. Agreso-victimogene typologies. Bucharest: Universul Juridic Publishing House. 